\title{
Gefitinib Monotherapy in Advanced non-small-cell Lung Cancer: A Retrospective Analysis
}

\author{
Shrestha S, Joshi P \\ Om cancer Care Center, Om hospital and Research Center, Chabahil, Kathmandu, Nepal,
}

\begin{abstract}
Introduction: There is no published data in Nepal regarding the use of gefitinib in patients with non-small cell lung cancer (NSCLC). Therefore, a retrospective analysis was conducted to evaluate the response and toxicity profile of Gefitinib alone in patients with advanced NSCLC and unknown epidermal growth factor receptor (EGFR) status.
\end{abstract}

Methods: A single institutional retrospective study was conducted for the period from January 2004 to December 2006 involving patients with locally advanced or metastatic NSCLC who received gefitinib as monotherapy Primary objective was to evaluate the objective tumor response rate.

Results: A total of 36 patients with advanced NSCLC who received gefitinib $250 \mathrm{mg}$ orally once daily as 1st, 2nd, 3rd, and 4th line treatment in 7, 14, 9, and 6 patients respectively were included in the analysis. Comparable number of patients pertaining to sex, smoking status, and tumor histology were included.

The overall response rate at 3 months was $60 \%$ including $47 \%$ in males and $68 \%$ in females. After one month $38 \%$ and $6.6 \%$ patients with adenocarcinoma and squamous histology respectively responded to gefitinib therapy. The median progression-free survival was 5.7 months. Toxicities were generally mild with diarrhea, rash and pruritus being the most commonly observed side effects.

Conclusion: In this single-center experience, gefitinib demonstrated clinically significant response in overall population and provided good palliation in pretreated patients.

Keywords: Advanced stage NSCLCs, EGFR-TKIs, Gefitinib, monotherapy, Nepal.

\section{INTRODUCTION}

Lung cancer is the most common cause of cancerrelated deaths in both men and women worldwide. ${ }^{1}$ Despite advances in treatment, such as combination chemotherapy and chemoradiation, survival has improved a very little over the past few decades. ${ }^{2} \mathrm{~A}$ meta-analysis demonstrated that the median survival time for patients with advanced disease receiving cisplatin-based chemotherapy is around 6 months. ${ }^{3}$ The 5 -year survival rate for all stages is $<15 \% .4$ Prognosis is particularly poor for patients who have progressive disease following chemotherapy. For non-small cell lung cancer (NSCLC) patients receiving best supportive care (BSC) after 1 or more prior chemotherapy regimen, median survival time is just 16 weeks, with a 1 -year survival rate of $16 \%{ }^{5}$. Recently, it has become generally accepted that systemic chemotherapy is beneficial in terms of improved survival and quality of life ( $\mathrm{OOL}$ ) in patients with advanced NSCLC. ${ }^{3,6}$ As more patients receive first-line chemotherapy, the need for effective second-line therapy is increasing. Currently, docetaxel, ${ }^{7}$

\footnotetext{
Correspondence:

Dr. Sudip Shrestha

Om Hospital and Research Center

Chabahil, Kathmandu, Nepal

Tel no: 9851041004

E-mail: sudipsh@hotmail.com
} 
pemetrexed, and EGFR inhibitors (erlotinib, gefitinib) are accepted as second-line therapy in patients who failed to respond to platinum-based regimens. Patients with late-stage NSCLC are often symptomatic, Therefore, improvements in disease-related symptoms and $\mathrm{QOL}$ are the key desired outcomes of medical management. ${ }^{8}$. EGFR is a promising target for anticancer therapy because it is expressed variedly in a variety of tumors, including NSCLC. ${ }^{9,10}$ Furthermore, high levels of EGFR expression have been associated with a poor prognosis in lung cancer patients in several studies. ${ }^{11-13}$ EGFRtargeted cancer therapies are currently being developed; strategies include inhibition of the intracellular tyrosine kinase domain of the receptor by small molecules such as Gefitinib. ${ }^{14}$ Gefitinib is an orally active, selective EGFR tyrosine kinase inhibitor (TKI) that blocks signal transduction pathways implicated in the proliferation and survival of cancer cells. ${ }^{9,10}$ Two phase II trials (IDEAL 1 and IDEAL 2), evaluated the efficacy of gefitinib in advanced NSCLC patients who received $\leq 2$ (IDEAL 1) or $\geq 2$ (IDEAL 2) previous chemotherapy regimens. These trials demonstrated that toxicity was mild and showed an encouraging response rate with an response rate of 18.4 and $11.8 \%$ of patients in the $250 \mathrm{mg}$ arm, respectively, and an improvement in disease-related symptoms and $\mathrm{QOL}$ was observed. ${ }^{11,12}$ In a recent randomised, placebo-controlled, phase III trial (ISEL), gefitinib failed to prolong survival compared to placebo in patients with advanced NSCLC who had failed one or more lines of chemotherapy. Subgroup analysis of ISEL suggested improved survival in patients of Asian origin and non-smokers. In addition, subset analyses of IDEAL and several retrospective studies have indicated that female gender, adenocarcinoma histology (especially bronchial alveolar carcinoma), non-smoker status and Asian ethnicity are factors which predict response to gefitinib. Appropriate patient selection by clinical characteristics or genetic information is needed, both for future clinical trials of Gefitinib and its routine use in the clinic among patients with advanced NSCLC. ${ }^{13}$

In Nepal, no published data exists so far regarding the use of gefitinib in NSCLC population. This is a first experience from Nepal (single institutional) regarding the use of gefitinib in the in advanced NSCLC population in chemo-naive and previously treated patients.

\section{METHODS}

This retrospective study was conducted at Om Hospital and Research center, Kathmandu, Nepal between January 2004 to December 2006. The NSCLC study subjects who received gefitinib during that period were followed up till end of June 2008. Primary objectives were to evaluate the objective tumor response rate (RR) for Gefitinib doses of 250 mg, secondary objectives were to estimate disease-related symptom improvement rate, disease control rate (response and stable disease), progression-free survival (PFS).

\section{Patient Population}

Patients at least 18 years of age with histologically or cytologically confirmed locally advanced or metastatic NSCLC (stage III/IV disease with at least one bidimensionally measurable lesion) not curable with surgery or radiotherapy were eligible for inclusion in the study. Patients with recurrent or refractory disease following previous chemotherapy regimens should have received at least one platinum agent. Patients had a World Health Organization (WHO) performance status (PS) of 0 to 4 with life expectancy of at least 12 weeks.

Patients were excluded from the study if they received systemic chemotherapy within 21 days, or radiotherapy within 14 days before the start of gefitinib; or presented with unresolved chronic toxicity, excluding alopecia, higher than grade 2 as per National Cancer Institute Common Toxicity Criteria (NCl-CTC) version 2 ; or presented with alanine aminotransferase (ALT) or aspartate aminotransferase (AST) levels $\geq 2.5$ times the upper limit of normal (ULN) ( $>5$ times of ULN in the presence of liver metastases); or presented with serum creatinine levels $>1.5$ times ULN, serum bilirubin levels $>1.25$ times ULN, and neutrophil count $<1.5$ $\times 109 / \mathrm{L}$, and platelet count $<75 \times 109 / \mathrm{L}$.

\section{Treatment and Assessments}

Patients recieved oral gefitinib $250 \mathrm{mg}$ once daily until disease progression, intolerable toxicity, withdrawal of consent, loss to follow up or death.

We assessed objective tumour response as complete response $(C R)$, partial response (PR), partial response in non-measurable disease (PRNM), stable disease (SD) or progressive disease (PD) in accordance with the Southwest Oncology Group modification of Union Internationale Contre le Cancer/ WHO criteria.17 CR was defined as disappearance of all known lesion(s) and confirmed at 4 weeks. PR was defined as at least $50 \%$ decrease and confirmed at 4 weeks. SD was defined as neither PR nor PD criteria met. PD was defined as $25 \%$ increase and no $C R$, PR or SD documented before increased disease, or new lesion(s). First clinical assessment was made on the 1 st week of start of chemotherapy with gefitinib, and there after weekly till good clinical recovery every 4th week. Radiological assessment was done in the first 4 th week of start of gefitinib, there after every 4 weeks until disease progression or complete response. Following $\mathrm{CR}$ assessment was done every 3 months till progression, lost to follow up or death. For patients who are stable beyond 6 months, assessment is done every 3 months or at the time of clinical deteriorations. 
Duration of response was defined as the time from the first objective assessment of CR or PR to the first instance of progression or death. Progression-free survival (PFS) was defined as the period from the start date of gefitinib to the date when disease progression (or death) was observed.

\section{RESULTS}

Baseline patient characteristics from the study are summarized in Table 1. Among 36 patients, 17 were male and 19 were female. $58 \%$ patients $(33 \%$ male and $67 \%$ female) were non-smokers and $42 \%(67 \%$ male and $33 \%$ female) patients were smokers. For the purpose of this study, non-smokers were defined as patients who had smoked $<100$ cigarettes in their lifetime. Out of 36 patients, 31 patients were $>50$ years age. About $30 \%$ patients had WHO PS $1.53 \%$ patients $(n=19)$ had stage IIIB and $47 \% \quad(n=17)$ patients had stage IV disease. About $39 \%$ of patients received 2 nd line gefitinib treatment.

Table 1. Patient characteristics

\begin{tabular}{|c|c|}
\hline \multicolumn{2}{|l|}{ Gender } \\
\hline Male & 17 \\
\hline Female & 19 \\
\hline \multicolumn{2}{|l|}{ Smoking status } \\
\hline Smokers & $15(\mathrm{M}-10, \mathrm{~F}-5)$ \\
\hline Non-smokers & $21(\mathrm{M}-7, \mathrm{~F}-14)$ \\
\hline \multicolumn{2}{|l|}{ Age: } \\
\hline$<40:$ & 1 \\
\hline 41-50: & 4 \\
\hline 51-60: & 14 \\
\hline 61-70: & 9 \\
\hline$>70:$ & 8 \\
\hline \multicolumn{2}{|c|}{ WHO performance status: } \\
\hline 0 & 3 \\
\hline 1 & 11 \\
\hline 2 & 9 \\
\hline \multirow{2}{*}{4} & 8 \\
\hline & 5 \\
\hline \multicolumn{2}{|l|}{ Diseases stage: } \\
\hline Stage IIIB: & 19 \\
\hline Stage IV: & 17 \\
\hline \multicolumn{2}{|l|}{ Disease Histology } \\
\hline Adenocarcinoma & 21 \\
\hline Squamous carcinoma & 15 \\
\hline \multicolumn{2}{|l|}{ Use of gefitinib: } \\
\hline 1st line: & 7 \\
\hline 2nd line: & 14 \\
\hline 3rd line: & 9 \\
\hline 4th line: & 6 \\
\hline
\end{tabular}

The mean duration of treatment was 7.8 months (median, 6.5 months). At the cutoff date for collection of data (end of June 2009), a total of 3 out of 36
$(8.3 \%)$ of the patients in the Gefitinib group were continuing to receive the study treatment.

\section{Efficacy}

The median PFS was 5.7 months. The 12 -month PFS rate was $31.43 \%$. Two-year and three-year PFS rates were $25.7 \%$ and $17 \%$ respectively.

Table 2. Response rates in NSCLC patients treated with gefitinib up to 3 years

\begin{tabular}{|c|c|c|c|c|}
\hline Duration & SD & PR & CR & PD \\
\hline $\begin{array}{c}1^{\text {st }} \\
\text { month }\end{array}$ & $\begin{array}{l}24 / 36 \\
(66.7 \%)\end{array}$ & $\begin{array}{l}9 / 36 \\
(25.0 \%)\end{array}$ & None & $\begin{array}{l}3 / 36 \\
(8.3 \%)\end{array}$ \\
\hline $\begin{array}{c}3^{\text {rd }} \\
\text { month }\end{array}$ & $\begin{array}{l}14 / 35 \\
(40.0 \%)\end{array}$ & $\begin{array}{l}5 / 35 \\
(14.3 \%)\end{array}$ & $\begin{array}{l}2 / 35 \\
(5.7 \%)\end{array}$ & $\begin{array}{l}14 / 35 \\
(40.0 \%)\end{array}$ \\
\hline $\begin{array}{c}6 \\
\text { months }\end{array}$ & $\begin{array}{l}10 / 35 \\
(28.5 \%)\end{array}$ & $\begin{array}{l}3 / 35 \\
(5.6 \%)\end{array}$ & $\begin{array}{l}2 / 35 \\
(5.7 \%)\end{array}$ & $\begin{array}{l}20 / 35 \\
(57.1 \%)\end{array}$ \\
\hline $\begin{array}{c}12 \\
\text { months }\end{array}$ & $\begin{array}{l}9 / 35 \\
(25.7 \%)\end{array}$ & $\begin{array}{l}0 / 35 \\
(0.0 \%)\end{array}$ & $\begin{array}{l}2 / 35 \\
(5.7 \%)\end{array}$ & $\begin{array}{l}24 / 35 \\
(68.6 \%)\end{array}$ \\
\hline $\begin{array}{c}18 \\
\text { months }\end{array}$ & $\begin{array}{l}8 / 35 \\
(22.8 \%)\end{array}$ & $\begin{array}{l}0 / 35 \\
(0.0 \%)\end{array}$ & $\begin{array}{l}2 / 35 \\
(5.7 \%)\end{array}$ & $\begin{array}{l}25 / 35 \\
(71.4 \%)\end{array}$ \\
\hline 2 years & $\begin{array}{l}7 / 35 \\
(20.0 \%)\end{array}$ & $\begin{array}{l}0 / 35 \\
(0.0 \%)\end{array}$ & $\begin{array}{l}2 / 35 \\
(5.7 \%)\end{array}$ & $\begin{array}{l}26 / 35 \\
(74.3 \%)\end{array}$ \\
\hline 3 years & $\begin{array}{l}5 / 35 \\
(14.3 \%)\end{array}$ & $\begin{array}{l}0 / 35 \\
(0.0 \%)\end{array}$ & $\begin{array}{l}1 / 35 \\
(2.8 \%)\end{array}$ & $\begin{array}{l}29 / 35 \\
(82.8 \%)\end{array}$ \\
\hline
\end{tabular}

The ORR after three months was 21/35 (60\%). On clinical assessment, clinical benefit (general well-being, improvement in respiratory symptoms) was appreciable on 14th day in responders. Clinical benefit in radiological responders is shown in table 3 . Out of 26 radiological responders at 2 months, 11 patients showed clinical benefit at 14th day and 22 patients showed clinical benefit at 4th week. Maximum clinical benefit was seen up to 3 months, after that clinical benefit was static.

Table 3. Clinical benefit in NSCLC patients treated with gefitinib upto 2 months

\begin{tabular}{cc}
\hline Duration & $\begin{array}{c}\text { Clinical benefit in radiological } \\
\text { responders } \\
2 \text { weeks }\end{array}$ \\
4 weeks & $11 / 26(42.3 \%)$ \\
& $22 / 26(84.6 \%)$ \\
\hline
\end{tabular}

On radiological assessment at 4th week, 9 out of 36 patients had PR whereas 3 patients had PD and 24 patients showed SD (figure 1). Radiological PR was consistently observed till 6 months of treatment. PR was observed in majority of the patients by 8 weeks (out of 16 patients with PR after 12 weeks, 11 patients showed PR within 8 weeks). Out of 11 patients with PR within 8 weeks, 2 patients achieved CR by 12 weeks and 3 patients achieved PR by 12 weeks and 6 months, 


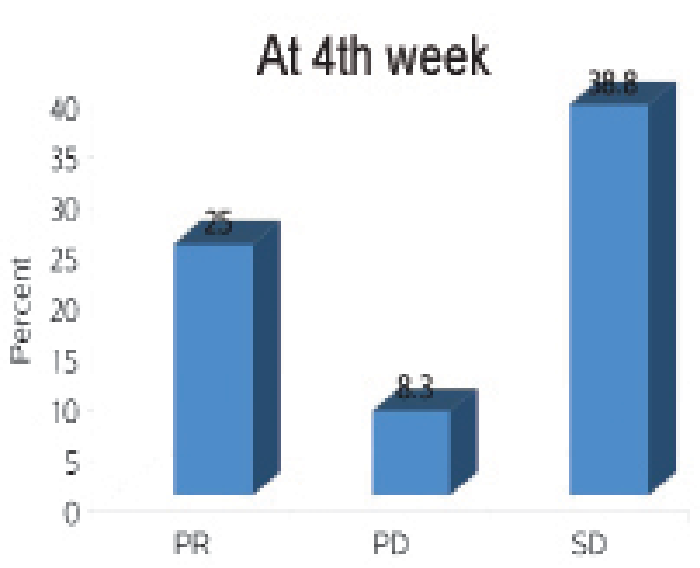

Figure 1. Radiological assessment in NSCLC patients treated with gefitinib at 4 th week

and for 6 patients disease was stable. Previous nonresponders still achieved PR till 12 week, whereas 2 patients with SD achieved PR. However, no more radiological $P R$ was observed beyond this time.

Two out of 35 patients had radiological CR. One patient received gefitinib as 2 nd line treatment after failure of previous gemcitabine and carboplatin; whereas second patient received gefitinib as 3 rd line threapy. Both of them were females with adenocarcinoma histology presenting primarily as pleural effusion. The first patient continued to be in CR till 2 years and later had brain metastasis, whereas the second patient continued to be in $\mathrm{CR}$ till 18th month and had locally progressive disease.

Among the responders at 3rd month (21 out of 35 ), male and female patients were $47 \%(7 / 35)$ and $68 \%(13 / 35)$ respectively. At 6 months, 7 out of 19 females and 13 out of 16 males had progressive disease respectively. At one year, 10 out of 19 females were responders, whereas out of 17 males only one was in stable disease. At 2 year, 8 females were still responding whereas only 1 male was having stable disease. At 42 months, 3 patients who were still on the gefitinib were all female. This indicates females patients responded better and response duration was shorter in male patients.

Patients with adenocarcinoma responded better than patients with squamous histology. At 1st month, majority of responders were of adenocarcinoma where 8 out of 21 achieved PR; whereas among patients with squamous histology only 1 out of 15 patients achieved PR and 2 patients had PD. In overall population, majority of response was observed at 2 months where 7 out of 21 adenocarcinoma patients and 4 out of 15 squamous carcinoma patients achieved PR. Majority of patients who had long lasting response were of adenocarcinoma subtype where 3 patients were still having stable disease after 3 years. Majority of patients with squamous subtype, who responded initially, progressed by 9 months; however, one patients had SD till 2 yrs who was male and ex- smoker.

At two months, 19 out of 21 non-smoking patients showed at least some benefit (11 SD + 8 PR); whereas, among smokers 7 out of 15 patients showed benefit (4 $\mathrm{SD}+3 \mathrm{PR})$. At 6 months, 14 non-smoking patients were still having some response (9SD $+3 P R+2 C R)$; whereas, only one smoker was having SD. None of the smoker had PFS $>9$ months where all the patients with PFS $>9$ months were non-smokers. Two patients who had CR were also non-smokers.

Overall response was observed more among chemonaive patients where, out of $7(71 \%)$ patients, 4 patients showed PR and 1 patients had SD. In patients who received gefitinib as 2 nd-line therapy ORR was $64 \%$ (5 $\mathrm{SD}+3 \mathrm{PR}+1 \mathrm{CR})$. ORR patients who received 3rd-line and 4 th-line gefitinib wer $55 \%(2 \mathrm{PR}+3 \mathrm{SD}+1 \mathrm{CR})$ and $33 \%(1 \mathrm{SD}+1 \mathrm{PR})$ respectively.

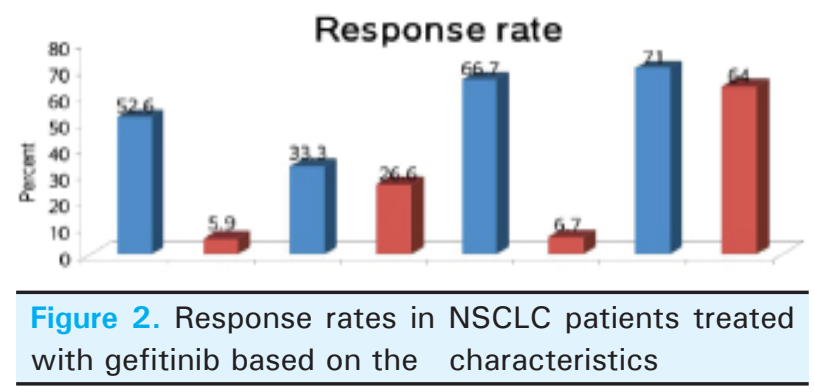

\section{Toxicities}

Toxicities were generally mild in this cohort of patients, with diarrhea and rash being the most commonly observed side effects. Rash and pruritus were observed in 11 patients ( 6 grade I, 3 grade II, 2 grade III). Diarrhea was observed in 6 patients ( 1 Grade III, 1 grade II and 4 grade I). Nausea and vomiting was observed in 5 patients ( 2 grade II and 3 Grade I). Treatment was discontinued for one patient due to grade III gastrointestinal toxicity (nausea and diarrhea). Asthenia was observed in two patients. No obvious interstitial lung disease was observed.

\section{DISCUSSION}

Gefitinib is an orally active, selective EGFR-TKI that blocks signal transduction pathways, and is one of the promising agents among targeted therapy used in the treatment of advanced NSCLC.14 Several clinical studies including IDEAL 1 and ISEL had shown higher overall survival and response rates with gefitinib in Asian patient population with advanced NSCLC. ${ }^{15,16,17}$ However, INTEREST study had shown that in pretreated patients, Asian ethnicity does not appear to be an important selection factor. The trial had also reported that although Asian patients had longer overall survival than the overall population, they did equally well when 
treated with gefitinib or docetaxel. ${ }^{18}$ In chemotherapynaive patients, there is no role for gefitinib in combination with doublet chemotherapy. ${ }^{19,20}$ IPASS study had demonstrated that gefitinib alone may be superior to doublet chemotherapy in terms of PFS in clinically selected Asian patients with advanced NSCLC.21 Ho et al., conducted a clinical study in 61 patients ( with $38 \%$ Asian patients) treated with gefitinib for advanced NSCLC. On radiologic review, 14 patients showed PR, 10 of whom were Asian, 10 were female patients, 8 were non-smokers, 8 patients had adenocarcinoma, and 4 patients had bronchoalveolar variant.22 In our study also gefitinib has shown higher response in female versus male patients $(52.6 \%$ vs. $5.9 \%)$, adenocarcinoma versus squamous histology $133.3 \%$ vs. $26.6 \%$ ), chemo-naive versus 2 nd-line therapy $(71 \%$ vs. $64 \%)$, and non-smokers versus smokers $(66.7 \%$ vs. $6.7 \%)$. IPASS study showed superior 1-year PFS rate of $24.9 \%$ with gefitinib compared with $6.7 \%$ with carboplatin-paclitaxel combination chemotherapy.23 In our trial the 1 year PFS was higher than the IPASS study (31.4\% vs. $24.9 \%$ ). The ORR at 3 months was $60 \%$. Out of $7(71 \%)$ patients, ORR was observed more in chemo-naive patients where 4 patients achieved PR and 1 patient had SD. ORR observed in patients receiving gefitinib as 2nd-line, 3rd-line, 4th-line was 64\% (5 SD $+3 \mathrm{PR}+1 \mathrm{CR}), 55 \%(2 \mathrm{PR}+3 \mathrm{SD}+1 \mathrm{CR})$, and $33 \%$ (1 SD + 1 PR) respectively. In the ISEL study, most patients experienced at least one AE $182 \%$ in gefitinib group and $71 \%$ in placebo group). The most common AEs in the gefitinib group were rash and diarrhea. In our study the toxicities were generally mild in advanced NSCLC patients, with diarrhea and rash being the most commonly observed side effects.

In this single-centre experience, gefitinib demonstrated clinically significant efficacy and safety. gefitinib shows better response in chemo naive patients but also useful even when it is used as 4th-line.
Studies are currently ongoing to further define the role of gefitinib in the treatment of advanced NSCLC, in Asian patients and elsewhere. Asian patients have been specifically targeted in current Phase II, III and IV trials. Further, larger prospective studies are needed in Nepal to study its effectiveness in the population with known EGFR mutation status.

\section{CONCLUSION}

In this single-center experience, gefitinib demonstrated clinically significant antitumor activity and provided good palliation in a predominantly pretreated group of patients. Our results, which are similar to other Asian countries, demonstrated better response and DFS among female, non-smoker, adenocarcinoma subtypes. Though it has better response when use in cheomonaive but also useful even when it is used as fourth line. Though EGFR status in not known in this study; prevalence of EGFR mutation status seems to be high in our population as reported from other Asian countries. Further larger prospective studies is needed in our country to study its effectiveness in the population with known EGFR mutation status.

\section{ACKNOWLEDGEIMENT}

We thank all the patients who were a part of this study. A special note of thank to Dr. Bijesh Ghimire and Mr. Raj Kumar Gautam of Om Hospital and Research Centre, Nepal for patient and data monitoring. We also thank Fresenius Kabi for supporting the study.

\section{REFERENCES}

1. Ferlay J, Bray F, Pisani P. GLOBOCAN 2000: Cancer Incidence, Mortality and Prevalence Worldwide, Version 1.0 (IARC, CancerBase No5). Lyon France, IARC Press, 2001.

2. Schiller J: Current standards of care in small-cell and non-small-cell lung cancer. Oncology 2001; 61:3-13, (suppl $1)$.

3. Non-small Cell Lung Cancer Collaborative Group: Chemotherapy in non-small cell lung cancer: A meta-analysis using updated data on individual patients from 52 randomised clinical trials. BMJ 1995; 311:899-909.

4. Ries L, Eisner M, Kosary C,: SEER Cancer Statistics Review, 1973-1998. Bethesda, MD, National Cancer Institute, 2001.
5. Fossella FV, Lee JS, Hong W: Management strategies for recurrent non-small cell lung cancer. Semin Oncol 1997; 24:455-462.

6. Klastersky J, Paesmans M: Response to chemotherapy, quality of life benefits and survival in advanced non-small cell lung cancer: Review of literature results. Lung Cancer 2001; 34:95-101(suppl 4).

7. Frances A. Shepherd, Janet D. Rodryg R., Karin M., Richard G., Mark $\mathrm{O}^{\prime}$ et al.Prospective randomized trial of docetaxel versus best supdportive care in patients with non-small-cell lung cancer previously treated with platinum-based chemotherapy. J Clin Oncol 2000; 18:2095-2103.

8. American Society of Clinical Oncology: Clinical practice guidelines for the treatment of unresectable non- small-cell lung cancer: Adopted on May 16, 1997 by the American Society of Clinical Oncology. J Clin Oncol 1997; 15:2996-3018. 
9. Negoro S, Nakagawa K, Fukuoka M. Final results of a phase I intermittent dose-escalation trial of ZD1839 (Iressa) in Japanese patients with various solid tumours. Proc Am Soc Clin Oncol 2001; 20:324a,(abstr 1292).

10. Ranson M, Hammond L, Ferry D, Kris M, Tullo A, Murray $\mathrm{Pl}$, et al: ZD1839, a selective oral epidermal growth factor receptor-tyrosine kinase inhibitor, is well tolerated and active in patients with solid, malignant tumors: Results of phase I trial. J Clin Oncol 2002; 20:2240-2250.

11. Fukuoka M, Yano S, Giaccone Tamura'T, Nakagawa K, Douillard JY, et al. Multi-institutional randomized phase II trial of Gefitinib for previously treated patients with non-small-cell lung cancer. J Clin Oncol 2003; 21:2237-46.

12. Kris M, Natale R, Herbst R, Lynch TJ, Prager D, Belani $\mathrm{CP}$ et al. A phase II trial of ZD 1839 ('Iressa') in advanced non-small-cell lung cancer (NSCLC) patients who had failed platinum- and docetaxel-based regimen (IDEAL 2). Proc Am Soc Clin Oncol 2002; 21:292a.

13. Tamura K, Fukuoka M. Gefitinib in non-small cell lung cancer. Expert Opin Pharmacother. 2005; Jun 6(6):985-93.

14. Kaneda H, Tamura K, Kurata , 1: Retrospective analysis of the predictive factors associated with the response and survival benefit of gefitinib in patients with advanced non-small-cell lung cancer. Lung Cancer 2004; 46(2):247-54.

15. Fukuoka M, Yano S, Giaccone G, Nakagawa K, Nishiwaki K Kudoh S et al: Multi-institutional randomized phase II trial of gefitinib for previously treated patients with advanced non-small-cell lung cancer. J Clin Oncol 2003; 21:2237-46.

16. Thatcher N, Chang A, Parikh P, Ciuleanu J, Pawel JV, Thongprasert $\mathrm{S}$ et al: Gefitinib plus best supportive care in previously treated patients with refractory advanced non-small-cell lung cancer: results from a randomised, placebo-controlled, multicentre study (Iressa Survival Evaluation in Lung Cancer). Lancet 2005; 366:1527-37.
17. Nishiwaki Y, Yano S, Tamura T, Nakagawa K, Kudoh S, Haroi $\mathrm{T}$ al: Subset analysis of data in the Japanese patients with NSCLC from IDEAL 1 study on gefitinib. Gan To Kagaku Ryoho 2004; 31:567-73.

18. Kim ES, Hirsch V, Mok T, Mark AS, Radj G, Yi- LW et al: Gefitinib versus docetaxel in previously treated non-small-cell lung cancer: a randomised phase III trial (INTEREST). Lancet 2008; 372:1809-18.

19. Giaccone G, Herbst RS, Manegold C, Scagliotti G, Rosell R, Miller $\mathrm{V}$ et al: Gefitinib in combination with gemcitabine and cisplatin in advanced non-small-cell lung cancer: a phase III trial-INTACT 1. J Clin Oncol 2004; 22:777-84.

20. Herbst RS, Giaccone G, Schiller JH, Natale RB, Miller V, Manegold G al: Gefitinib in combination with paclitaxel and carboplatin in advanced non-small-cell lung cancer: a phase III trial-INTACT 2. J Clin Oncol 2004; 22:785-94.

21. Mok $\mathrm{T}, \mathrm{Wu} \mathrm{YL}$, Thongprasert $\mathrm{S}$, Yang $\mathrm{CH}$, Chu DT, Saijo N et al: Phase III, randomised, open-label, first-line study of gefitinib versus carboplatin/paclitaxel in clinically selected patients with advanced non-small-cell lung cancer. Ann Oncol 2008; 19(Suppl. 8) (viii1, Abstract LBA2).

22. Ho C, Murray N, Laskin J, Melosky B, Anderson S, Bebb G: Asian ethnicity and adenocarcinoma histology continues to predict response to gefitinib in patients treated for advanced non-small cell carcinoma of the lung in North America. Lung Cancer 2005; 49:225-31.

23. Mok TS, Wu YL, Thongprasert $\mathrm{S}$ Yang $\mathrm{CH}$, Chu DT, Saijo $\mathrm{N}$ et al: Gefitinib or carboplatin-paclitaxel in pulmonary adenocarcinoma. N Engl J Med 2009; 361(10):947-57. 